\title{
Análisis del hambre en el estado de Zacatecas bajo el modelo de Mínimos Cuadrados Ordinarios
}

\section{Analysis of hunger in the state of Zacatecas under the model of ordinary least squares}

\author{
Louis Valentin-Mballa* \\ Arely Yesenia Sauceda-Quintero**
}

\begin{abstract}
The purpose of this article is to make a quantitative analysis of the problem of hunger in the state of Zacatecas in Mexico. The variables considered for the realization of the model are: years of schooling, inhabitants per dwelling, gross aggregate value, economically active population, gross domestic product, and number of hectares harvested, in each of the 58 municipalities of Zacatecas. Through a re-categorization of the ordinary least squares (OLS) method, we conclude that the number of inhabitants per household is the most important factor when determining the probability of suffering from hunger in that state.
\end{abstract}

Keywords: financial deregulation, food shortage, poverty, hunger, ordinary least squares.

\section{Resumen}

El objetivo del presente artículo es hacer un análisis cuantitativo de la problemática del hambre en el estado de Zacatecas en México. Las variables tomadas en cuenta para la realización del modelo son años de escolaridad, habitantes por vivienda, Valor Agregado Bruto, Población Económica Activa, Producto Interno Bruto $y$ número de hectáreas cosechadas, en cada uno de los 58 municipios de Zacatecas. A través de una recategorización del Método de Mínimos Cuadrados Ordinarios (MCO) se llega a la conclusión de que el número de habitantes por vivienda es el factor más importante al momento de determinar la probabilidad de padecer hambre en dicho estado.

Palabras Clave: desregulación financiera, carencia alimenticia, pobreza, hambre, Mínimos Cuadrados Ordinarios. 


\section{Introducción}

La carencia alimenticia no puede ser tratada como un simple problema de falta de alimentos por ingresos insuficientes, sino como un asunto complejo que involucra la intervención de muchos actores. En realidad, el hambre tiene muchos rostros y éstos no pueden ser tratados de forma homogénea. A este respecto, la literatura es abundante. A inicios del siglo XXI, por ejemplo, Quispe-Cornejo (2000) consideró que existían básicamente dos corrientes que dominaban la interpretación del fenómeno del hambre: la marxista-leninista y la corriente del problema social. Según la autora, la primera enfatiza el aspecto demográfico del problema de la alimentación en los países subdesarrollados y en vías de desarrollo, con un enfoque crítico de las ideas burguesas. Por su parte, la segunda analiza el problema del hambre desde el punto de vista de su desarrollo histórico. Ambas corrientes convergen en que el hambre en la actualidad, obedece a ciertas lógicas de la crisis del capitalismo en determinada dimensión espaciotemporal. Por su parte, Rufin (2004) afirma que en los años 70, el hambre solía asociarse sobre todo al subdesarrollo; luchar contra el hambre consistía entonces en excavar pozos, aportar asistencia técnica a los agricultores y organizar el desarrollo.

Obviamente, estas posturas o antecedentes desde el punto de vista analítico, en la actualidad quedan cortas o tienden a ser insuficientes para una comprensión cabal u holística del "complejo fenómeno del hambre" (López y Martínez 2002; Ochoa y Muñoz-Muñoz, 2014; ArguetaMondragón y Carrazón-Alocén, 2014). En el caso específico de Zacatecas, los orígenes e impactos, las causas y manifestaciones de la carencia alimenticia son múltiples. Esto se debe principalmente a que el lugar donde viven las personas es un factor importante al momento de definir las oportunidades a las que tienen acceso, así como los desafíos que enfrentan; por lo cual, el problema del hambre merece ser analizado desde varias perspectivas.

En realidad, en las actuales condiciones sociales en México, la reproducción de la vida cotidiana de las familias en contextos de pobreza tiene como escenario el lugar donde vive la gente. Desde allí, las familias despliegan una serie de estrategias para cubrir sus necesidades básicas. Como lo plantea Ceja-Mena (2004), para el desarrollo de cualquier Estado es indispensable contar con una visión de cambio y crecimiento constante para el beneficio de la ciudadanía; este cambio depende, en gran medida, de la capacidad estratégica y administrativa en su modo de planeación e implementación de políticas públicas, que ayuden al desarrollo sociopolítico y económico de los diversos actores que participan en la dinámica funcional del Estado. 
En México, cubrir las necesidades (en todos los ámbitos) de los ciudadanos es un desafío importante relacionado con la gran desigualdad en el modo de distribución de la riqueza nacional. Asimismo, las necesidades del pueblo mexicano tienen muchas dimensiones, tales como la potencialización de las capacidades humanas, la educación, la salud, la seguridad, el acceso a la infraestructura y los ingresos, entre otros; sus efectos, de igual manera, son multifacéticos y multidimensionales y, en general, se traducen en pobreza, hambre, inseguridad, vulnerabilidad y exclusión o marginación social.

La negación de estas múltiples dimensiones y realidades puede concebirse como una aproximación imperfecta a la noción de bienestar en términos de libertad o capacidad de una persona para elegir el manejo de su vida. Asimismo, resolver los problemas públicos como el hambre, depende en gran medida de la conjunción de los polos de toma de decisiones de los gobiernos, así como de las capacidades de los ciudadanos y de su habilidad para convertirse en "seres y haceres" (Mballa, 2017a). Dicha habilidad está determinada en gran medida por el contexto políticoeconómico en el que vive la gente y sobre todo, por las oportunidades de un trabajo productivo. Los esfuerzos coordinados entre las diferentes estancias del gobierno y los actores de los demás sectores (académico, empresarial, sociedad civil, etc.) permiten sostener el desarrollo económico y social de las comunidades en desventaja.

Por lo tanto, en este artículo, se busca aprovechar el modelo econométrico de regresión lineal múltiple con el método de Mínimos Cuadrados Ordinarios para analizar cuantitativamente la problemática del hambre en el estado de Zacatecas. En primer término, la investigación plantea que la desregulación financiera ha influido en el sector agrícola en esa entidad federativa, ya que el libre mercado en dicho sector, sin duda alguna, ha afectado las condiciones de vida de los ciudadanos. En este sentido, el Tratado de Libre Comercio de América del Norte (TLCAN) ha profundizado la dependencia alimentaria para la población mexicana en general y para la del estado de Zacatecas, en particular.

En segundo lugar, después de una revisión de algunos datos generales sobre el estado de Zacatecas, resultó necesario analizar la problemática del hambre, sus principales causas y consecuencias a través de fuentes estadísticas nacionales y estatales. Con base en dichas fuentes, se elaboró una gráfica que muestra el Valor Agregado Bruto (VAB), la Población Económica Activa (PEA) y el Producto Interno Bruto (PIB) por municipio en Zacatecas, datos claves en la investigación, que permitieron la construcción del modelo.

En tercer lugar, se ha aprovechado el modelo econométrico para analizar esa problemática del hambre en Zacatecas. Dicho análisis se fundamenta 
en el modelo de Mínimos Cuadrados Ordinarios con una justificación de las variables tomadas en cuenta para realizar dicho modelo. En efecto, como se demuestra en la investigación, el análisis de regresión múltiple puede emplearse para construir mejores modelos que permiten la comprensión de la realidad social. En este caso en particular, se muestran los resultados arrojados por dicho modelo así como su explicación en relación con la problemática del hambre.

\section{Marco conceptual: la desregulación financiera y su impacto en el sector agrícola en México}

La desregulación económica en el sentido amplio del término, resulta de una restricción relacionada con alguna actividad económica, impuesta por el gobierno a los diversos actores socioeconómicos. Se refiere a la liberalización de las fuerzas competitivas y la "no" obstaculización a la entrada y salida del mercado, que son sinónimo de la libertad de competencia (Ramírez-Hernández, 2007). Es decir, el libre mercado en toda la expresión de la palabra, y todo lo que éste conlleva, incluidas las crisis en las que se ve inevitablemente inmerso.

Los ajustes estructurales en América Latina a lo largo de la década de los ochenta del siglo pasado, siguieron fielmente los postulados del "Consenso de Washington” (Ornelas-Delgado, 2007). Asimismo, la privatización y la desincorporación de empresas públicas fueron esenciales en los procesos de reformas estructurales en México. La primera fase comenzó en 1985 con la privatización de empresas paraestatales. La segunda se dio de 1989 a 1996, marcada por la renta de empresas grandes con poder de mercado (Kuntz-Ficker, 2010); con ello, la intervención del Estado dio un giro radical, lo que tuvo como consecuencia el abandono de la estrategia que identificaba los sectores con potencial. Se volvió a lo ortodoxo, es decir, dejar al mercado hacer su juego y que las fuerzas del mismo hicieran lo suyo.

En México, la primera generación de reformas estructurales promovidas por las instituciones de Bretton Woods (Banco Mundial, Fondo Monetario Internacional, Banca Multilateral, etc.) iniciaron con el expresidente Miguel de la Madrid; su gobierno representó un parteaguas en el actual sistema político mexicano, por acabar con el "estado de bienestar" e incorporar plenamente a México en el modelo neoliberal. Con la política de Miguel de la Madrid, los cambios provocados en el campo mexicano se profundizaron en el sexenio de Salinas de Gortari, que con el pretexto de promover las reformas necesarias para el desarrollo del sector agropecuario, puso en marcha el Plan Nacional de Modernización del 
Campo, con un planteamiento de un conjunto de lineamientos, para eliminar la política proteccionista y la apertura comercial del sector. Ante la falta de apoyos gubernamentales para que los campesinos cultiven la tierra, muchos ejidatarios se transformaron en jornaleros de sus propias tierras.

A su vez, en la gestión de Ernesto Zedillo (1994-2000), la política exterior de México se enfocó, primero, a la resolución de la crisis financiera de 1994 y, después, a la búsqueda de un tratado de libre comercio con la Unión Europea. La administración de Vicente Fox fue muy conservadora, pues sólo actuó para administrar los equilibrios macroeconómicos, sin arriesgar nada para estimular el crecimiento (Ornelas-Delgado, 2007). El presidente Calderón heredó de su antecesor una política exterior dislocada, sujeta a las agendas personales de miembros del gabinete pero, sobre todo, seriamente limitada por la visión aldeana del expresidente inmediato anterior, incapaz de valorar la tradición diplomática de México (Levy, 2009). El sexenio de Enrique Peña Nieto, actual presidente de México, se ha basado en el desarrollo de las "Reformas estructurales" las cuales, según sus creencias y convicciones, fomentan un ambiente propicio para el desarrollo empresarial, al fundamentarse en el free market, que busca la atracción de la inversión y tecnología extranjera.

Con una población creciente, una economía en expansión y un sector agrícola más orientado al mercado, México se ha convertido en el tercer socio de comercio agrícola más grande de Estados Unidos (después de Canadá y los 27 países de la Unión Europea) en términos de exportaciones e importaciones combinadas. En 2008, México representó alrededor de $13.9 \%$ de las exportaciones agrícolas de EE. UU. y 13.5\% de las importaciones, tal como se definen y clasifican por el USDA (United State Department of Agriculture). Entre 1993 (el último año antes de la implementación del TLCAN) y 2008, las exportaciones agrícolas de EE. UU. a México se expandieron a una tasa anual de $10.4 \%$, mientras que las importaciones agrícolas de México crecieron a una tasa de 9.7\% (Crawford, 2011).

En este sentido, la crisis alimentaria, que pudiera ser considerada como una consecuencia más del capitalismo, obedece a la lógica de una desregulación financiera y económica de un país (Calderón-Salazar, 2014). En el contexto del modelo neoliberal, un orden agroalimentario global está totalmente interconectado en la forma de funcionamiento del régimen de acumulación. Según Rubio (2013), los bienes básicos para la alimentación han orientado este orden mundial agroalimentario, esencialmente hacia las exportaciones. Quienes lideran los mercados mundiales en ese ámbito son los países desarrollados que desvalorizan las materias primas de origen agropecuario en orden de contrarrestar la caída de la cuota de 
ganancia; esto permite reducir costos de producción, para así exportar y vender a precios por debajo (inclusive y aunque parezca una paradoja) de sus costos de producción.

Esta tendencia se da por ser países altamente competitivos a todos los niveles, lo cual permite que sus gobiernos otorguen fuertes subsidios a los productores agrícolas. En este sentido, las empresas trasnacionales logran desplazar a productores locales, con ayuda de acuerdos comerciales que permitan aranceles de importación muy bajos. Estos precios reducidos se imponen como referentes en el mercado mundial, significando esto una competencia desleal frente a los agricultores de menor rango, como son la mayoría en el estado de Zacatecas.

En ese marco de la desregulación financiera, se introdujo un "sistema financiero sombra" (shadow banking) que abrió la puerta al capital especulativo en el ámbito de las materias agrícolas. A juicio de Vega-Mena et al. (2013), la desregulación financiera y los ajustes subyacentes han implicado una drástica reducción de la cobertura financiera en el sector agropecuario en México, por lo cual, según los censos agropecuarios 1991 y 2007 , las unidades de producción agrícola o forestal tuvieron acceso a 19\% del financiamiento de sus actividades en 1991 y tan solo 4\% en 2007.

Asimismo, los mercados de materias primas pudieron entrar en el sector de las especulaciones financieras y, sobre todo, en la mira de los index investors que buscan inversiones a largo plazo, atesorando mercancías por largos periodos. Así, se comenzó a impactar en el mercado de las materias primas, provocando alzas de precios a pesar de no existir cambios reales en el comportamiento de la oferta y demanda. Sin embargo, según Rubio (2013), el aumento de precios internacionales en productos básicos del sector agrícola no se transmitió a los nacionales debido a una marcada oligopolización en el mercado de granos y el aumento de precios en los insumos provocado por el incremento del precio del petróleo. Esta situación se ha agudizado con los planteamientos del TLCAN, poniendo a México en una situación de dependencia en productos agropecuarios.

\section{El Tratado de Libre Comercio de América del Norte (TLCAN) como factor de dependencia alimentaria}

El Tratado de Libre Comercio de América del Norte (TLCAN) es un acuerdo de amplio alcance que establece las reglas que rigen el comercio y las inversiones entre Canadá, Estados Unidos y México (TLCAN, 2012). Desde que el tratado entró en vigor, el 1 de enero de 1994, el TLCAN ha eliminado gradualmente las restricciones al comercio y a la inversión entre los tres países de la región de América del Norte. Como lo sustentan 
Mella y Mercado (2006), dadas las características de la economía agropecuaria mexicana y las políticas de apoyo al sector en los tres países miembro, ha habido efectos favorables para el desarrollo de un grupo de productos y productores, así como consecuencias restrictivas en otro grupo de la economía agropecuaria mexicana. Para estos autores, las características del sector agrícola mexicano en el marco del TLCAN destacan lo siguiente: 1. Hay problemas de competitividad con el exterior en términos de subsidios y otras fuentes de abatimiento de costos; 2 . Persiste un dualismo estructural (moderno y exportador frente al tradicional y de autoconsumo destinando excedentes al mercado); 3. El comercio es especializado (concentrado en Estados Unidos) y no intraindustrial, y 4. La inversión extranjera directa agropecuaria se ha contraído y ha registrado una creciente participación de Estados Unidos.

Por su parte, Arámbula-Reyes (2008) sostuvo que el TLCAN brinda a las empresas de América del norte un mejor acceso a los materiales, las tecnologías, los capitales de inversión y talentos disponibles en toda la región. En este mismo sentido, Romero (2017), con base en estadísticas oficiales, afirma que el TLCAN ha sido profundamente desfavorable para México; a consideración del autor, después del desplome de la producción agrícola mexicana debido a la competencia a la que se vieron sometidos los agricultores con los de EE. UU. y de Canadá en el marco del TLCAN, casi $80 \%$ del arroz, 31\% del maíz, 65\% del trigo, $40 \%$ de la carne de cerdo, $16 \%$ de la carne de aves y más de $16 \%$ de la leche, son importados.

La propia agencia Food Secure Canada (2012) asegura que el TLCAN para el sector agropecuario ha profundizado la dependencia alimentaria de México en cereales, oleaginosas, carne de bovino, porcino y productos lácteos, perdiéndose así su soberanía alimentaria. Por su parte, Crawford (2011) reafirma que 70\% de las importaciones agrícolas de México hacia sus dos socios del Tratado consisten en verduras, frutas y cerveza, gracias a la experiencia histórica de México en la producción de bebidas alcohólicas y su amplia gama de frutas y verduras.

En efecto, la agricultura en México en el marco del TLCAN ha mostrado un nuevo rostro en la agroindustria que ha internacionalizado su producción, empezando con los contratos de comercio en cultivos tradicionales. Tal integración ha generado todo un nuevo modo de unificación industrial mediante contratos de producción, "paquetes" tecnológicos para industrias enteras y formas no equitativas de control internacional sobre la producción agrícola (Losch, 2016). También ha significado que la distinción entre los procesadores en agronegocios nacionales y multinacionales caiga en esquemas de homogenización de la producción alimentaria. 
En la literatura actual, varios autores (Rivera de la Rosa et al., 2014; Urquía, 2014; Sánchez-Cano, 2014; Vela-Martínez y Armenta-Ramírez, 2015; Acosta-Acosta, 2017; Moral-Barrera y Murillo Villanueva, 2015) enfatizan esta dependencia alimentaria de México ante sus socios del TLCAN. Asimismo, los planteamientos de estos autores justifican la afirmación de Sánchez-Juárez (2013) al respecto de la dependencia alimentaria de México, agudizada por la implementación del TLCAN, la cual ha provocado que el sector agrícola ya no esté básicamente destinado a producir alimentos para la población nacional, debido a que dicho sector funciona como "sector insumo" para los agronegocios y el comercio transnacional.

Del mismo modo, la urbanización del trabajador rural es un hecho derivado de la contraposición entre la creciente despoblación rural con la ascendente necesidad de fuerza de trabajo estacional en el medio rural. Así, el trabajador rural en el marco del TLCAN debe competir con trabajadores urbanos por un puesto de trabajo, pero en la realidad se da un hecho contrario, ya que el trabajador rural debe contrapesar la falta de trabajo en el medio rural con trabajo urbano. Existe una tensión en la búsqueda de trabajo, ya que la ciudad no ofrece para este trabajador una fuente de empleo seguro (Tolón-Becerra y Lastra-Bravo, 2008). Con la investidura de Donald Trump como presidente de EE. UU., el destino del TLCAN ha caído en una incertidumbre innegable, con el riesgo de generar nuevos nichos de pauperización de la ciudadanía en desventaja.

El índice de dependencia alimentaria se define como "la proporción que las importaciones cubren del consumo nacional”, Moreno-Sáenz et al. (2016) han demostrado que este índice de dependencia de México frente a EE. UU., en el marco del TLCAN es de 43\%, lo cual coloca a México en una posición desfavorable ante cambios exógenos; según estos autores, ese elevado índice de dependencia explica la deterioración de las condiciones de vida de los agricultores mexicanos y sus familias; por tal motivo, la readaptación productiva derivada de la modernización e industrialización, como lo exige el TLCAN, no ha resuelto los problemas del campo mexicano.

En su informe presentado en el periódico El Financiero, Chávez (2014) mostró con precisión las características de esa dependencia alimentaria de México ante EE. UU. en el marco del TLCAN. Las gráficas siguientes ilustran ese fenómeno.

Como puede observarse en estas gráficas y a juicio del autor, la soberanía alimentaria en México se ha estancado desde la entrada en vigor del TLCAN; en los últimos 20 años la dependencia alimentaria de México ha registrado un crecimiento sostenido, pasando de $10 \%$ en 1994 a $43 \%$ en 2013, a pesar de que el país ha destacado como exportador de cerveza, 


\section{Gráfica 1}

\section{Panorama general de la dependencia alimentaria de México}
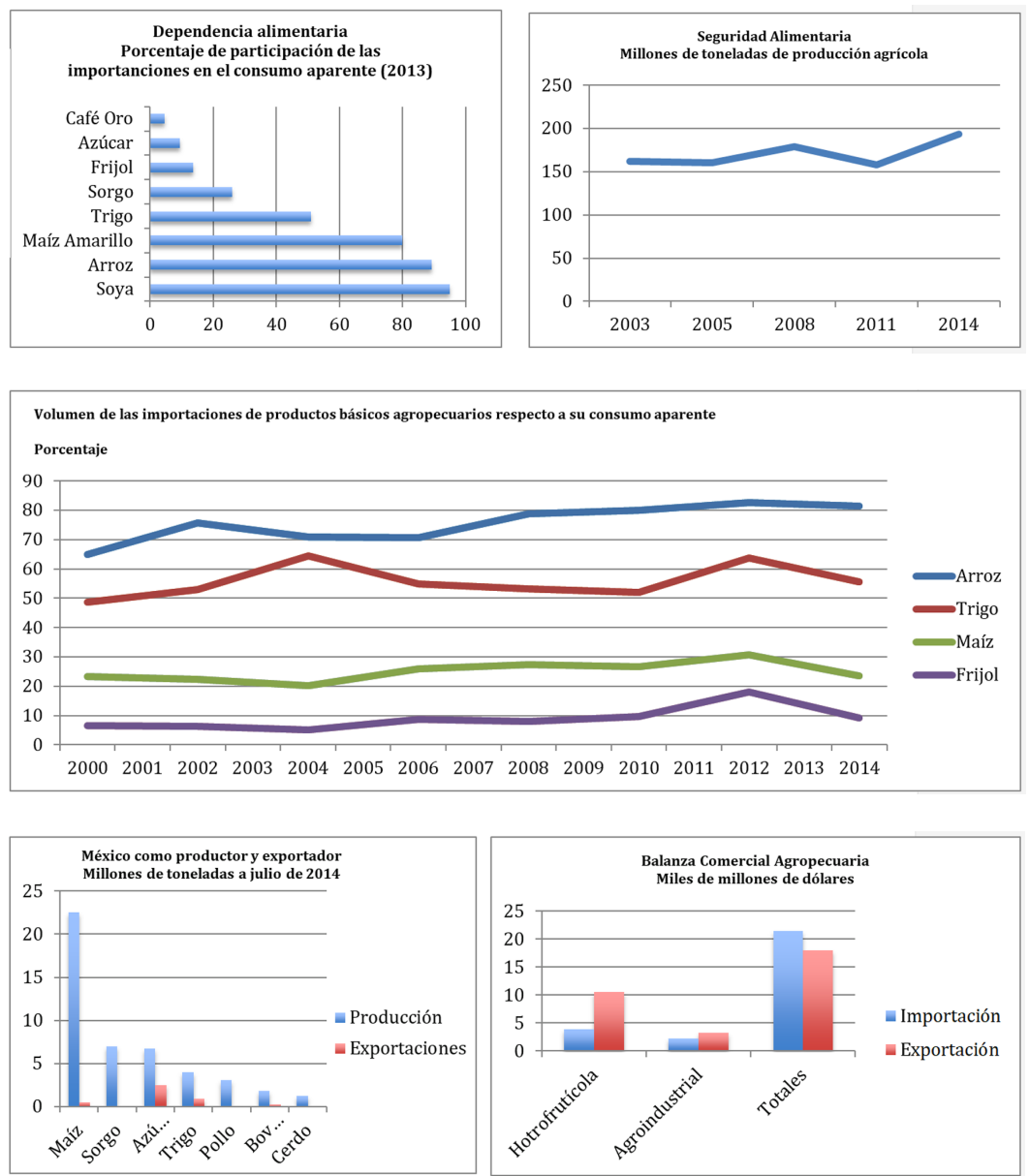

Fuente: Chávez, 2014.

tomate fresco, aguacate, berries, chiles y tequila. De acuerdo con cifras oficiales del Instituto Nacional de Estadística y Geografía (Inegi), mientras que en 1994 se importaron alimentos por un total de 1800 millones de dólares, en 2013 esa misma factura fue por 21,407,000; es decir, la balanza comercial agroalimentaria de México fue deficitaria por más de 3,374,000 de dólares (Chávez, 2014).

En este marco, destaca claramente que los resultados en el sector agropecuario son negativos; las expectativas que se tenían con el TLCAN no se han cumplido debido a que México no ha logrado aprovechar las ventajas competitivas en ese contexto de regionalización de los intercam- 
bios. Además, los problemas estructurales del agro mexicano como el atraso tecnológico, la falta de infraestructura e inversión de largo plazo han agudizado la dependencia alimentaria del lado mexicano.

En fin, podemos situar los intercambios agropecuarios en un marco del TLCAN y la dependencia alimentaria subsecuente, en la lógica de las asimetrías1 en la cooperación internacional. Mientras que México adquiere de sus socios del TLCAN (principalmente de EE. UU.) los productos estratégicos para la alimentación del pueblo mexicano, como los ya mencionados, los norteamericanos adquieren alimentos "suntuarios y periféricos" para su alimentación, como la cerveza, el vino, el café o las frutas frescas. Esto indica claramente que en el marco del TLCAN, el intercambio en el ámbito agropecuario está basado en una relación asimétrica de complementariedades, que al final son nocivas para el campo mexicano, lo cual ha generado procesos de pauperización en la población.

\section{La pobreza y el hambre: representación de los problemas públicos en México}

Los datos precedentes sobre el estado de Zacatecas están alineados a la situación general de la pobreza en México, con mayor concentración en el sur y sureste del país, pero con matices que evidencian a otras entidades (Coneval, 2015). Datos recientes del Consejo Nacional de Evaluación (Coneval, 2017) indican que a pesar de la disminución, la pobreza en términos porcentuales (en comparación con el 2014), cuatro de cada 10 habitantes en México en 2016 se encontraban en situación de pobreza, equivalente a $53,418,151$ personas y a $43.6 \%$ de la población nacional y distribuidas de la siguiente manera:

- Población en situación de pobreza en zonas rurales

$58.2 \%$

- Población en situación de pobreza en zonas urbanas

- Población hablante de lengua indígena

$39.2 \%$

- Población no hablante de lengua indígena

$77.6 \%$

- Mujeres en situación de pobreza $41.0 \%$

- Hombres en situación de pobreza $44.0 \%$ $43.0 \%$

${ }^{1}$ En los procesos de regionalización los intercambios como el TLCAN, las asimetrías pueden examinarse no sólo por ámbitos o dimensiones principales (ambientales, económicas, culturales y políticas), sino también por las concretas posiciones y relaciones de poder que se establecen entre los Estados miembro en cada una de esas dimensiones. En un extraordinario documento elaborado por el Sistema Económico Latinoamericano y del Caribe (SELA) en 2007, las posiciones de poder en este caso, son consideradas como el conjunto de capacidades que poseen determinados actores (Estados, organizaciones sociales, grupos étnicos, etc.) para imponer sus propios fines en los procesos sociales que les interesan o competen. 
- Menores de 18 años,

- Jóvenes de 12 a 29 años

- Adultos mayores

Ahora bien, más allá de sus innumerables definiciones y aproximaciones, la pobreza es una condición socioeconómica y política en la cual las personas viven con muy bajos niveles de bienestar (Flores-Alonso, 2012). En las agendas del gobierno mexicano, el tema de la pobreza como problema público $^{2}$ siempre ha ocupado un lugar preponderante. Esto significa que las políticas de combate a la pobreza y el hambre subsecuente se han incluido permanentemente en las agendas del gobierno, aunque sus dimensiones y características han variado en función de las ideologías dominantes, las condiciones macroeconómicas vigentes y las visiones de gobernanza en diferentes momentos (Mballa, 2015).

En efecto, la sistemática transición de la pobreza en problema público tiene implicaciones trascendentales en la determinación de la agenda gubernamental, ya que implica un efecto de exclusión o inclusión debido a que todas las necesidades no pueden formar parte de la agenda del gobierno (Ibarra-Cortés y Mballa, 2017). En México, la complejidad de esta transición nunca ha sido consecuente ni a priori; más bien ha resultado de una pugna incesante entre las autoridades legítimas (gobierno) y el conjunto de actores en situaciones de pobreza. Es precisamente en este sentido que Flores-Payan y Salas-Durazo (2018) aseveran que las acciones gubernamentales para la atención de problemáticas y demandas de grupos socialmente vulnerables se constituye en la identificación de las causas y los efectos que tiene una situación o condición específica en una población en particular para así incluirlo en la agenda pública.

El reconocimiento de la pobreza como una realidad problematizable es lo que Roth-Deubel (2014) denomina "representación de los problemas públicos". Esto significa que la inclusión de la pobreza y el hambre subsecuente en la agenda del gobierno en México es resultado de la tensión entre la "objetividad/subjetividad/racionalidad" del gobierno y la "obje-

\footnotetext{
${ }^{2}$ Becker (1995) considera que un cierto problema es reconocido como problema público cuando principalmente es propiciado por carencias objetivas de la sociedad y, por consecuencia, se ve incluido en la agenda del gobierno por autoridades con poder. Asimismo, la inclusión de la pobreza en la agenda gubernamental obedece a ciertas características intrínsecas de la naturaleza y la esencia de las necesidades sociales. Algunas de esas características son eslabones de los sistemas complejos: se trata básicamente de la interdependencia y dinámica funcional del fenómeno de la pobreza. La interdependencia implica que el fenómeno de la pobreza se revela no como un problema aislado de otros fenómenos de la vida social, si no que forma parte de un sistema complejo con un alto grado de multicausalidad en su origen y razón de ser. El carácter dinámico de la pobreza alude a que el subsistema de necesidades se reinvente y reconstituya permanentemente, siempre y cuando esté funcionalmente relacionado con el subsistema de los problemas públicos, es decir, con la agenda del gobierno.
} 
tividad/subjetividad/racionalidad" de los actores en situación de pobreza o hambre.

Gran parte de las iniciativas públicas para combatir la pobreza en México se insertan en el paquete de los programas sociales (Solidaridad, Progresa, Oportunidades, la Cruzada Nacional contra el Hambre, etc.). En el estado de Zacatecas, la persistencia de la pobreza, a pesar de la implementación de diferentes políticas públicas y programas sociales para su combate, tiende a ser el resultado de procesos incongruentes e inacabados de los actores de toma de decisiones.

La Organización de las Naciones Unidas para la Alimentación y la Agricultura (FAO, 2017) define a las personas con hambre (personas subalimentadas) como aquellas que habitualmente no comen lo suficiente para llevar una vida activa. Esto significa que el hambre es una consecuencia de la pobreza en su dimensión extrema. El sector alimentario y el sector agrícola ofrecen soluciones claves para el desarrollo y son vitales para la eliminación del hambre y la pobreza. En este sentido, la FAO (2017) considera que gestionadas de forma adecuada, la agricultura, la silvicultura y la acuicultura pueden suministrar comida nutritiva a todo el planeta, así como generar ingresos decentes, apoyar el desarrollo de las personas del campo y proteger el medio ambiente. Actualmente en zacatecas, la pobreza alimentaria es uno de los principales problemas que materializa la marginación social; de acuerdo con estadísticas de Inegi, Zacatecas acarrea profundas carencias, de 1,579,000 zacatecanos, 850,000 son pobres; 300,000 pobres alimentarios y 89,000 pobres extremos (Castro, 2016).

Ahora bien, el reconocimiento de la pobreza y el hambre subsecuente como problemas públicos, su agendación e institucionalización no obedecen a ninguna fórmula de acción política preestablecida (Roth-Deubel, 2007). Este proceso requiere de un análisis y comprensión de los alcances, efectos y avatares de dichos problemas públicos, para ingeniar las políticas públicas necesarias en pro de su combate. Esta perspectiva que se cristaliza en la toma de decisiones le confiere un carácter de constructo social a las políticas públicas de combate a la pobreza, al hambre y a la marginación social, con base en la racionalidad de los diferentes actores involucrados en el proceso.

La experiencia en México ha demostrado que gran parte de las estrategias de combate a la pobreza y sus derivados han tenido un enfoque generalmente asistencialista-paternalista (los programas sociales mencionados anteriormente); la propuesta de esos enfoques en lugar de erradicar dichos problemas públicos los nutre y los perpetúa. En el marco de este artículo, consideramos que la orientación de las políticas de combate a la 
pobreza y al hambre han de descifrar la complejidad de esos problemas públicos. Descifrar esa complejidad implica contemplar, al menos:

- La presencia o ausencia de cortes culturales

- La presencia o ausencia de cortes étnicos, raciales o religiosos

- La presencia o ausencia de cortes regionales o geográficos

- La presencia o ausencia de condiciones "estacionales" (por ejemplo, "nuevos" pobres versus pobres "históricos")

- El impacto diferencial de la pobreza y del hambre sobre diversos subgrupos vulnerables, inclusive en grupos pobres que no muestren ninguno de los cortes arriba mencionados

- La concepción de que la pobreza y el hambre golpean diferencialmente a mujeres, niños, adolescentes, hombres o discapacitados (Mballa, 2017a).

Como bien lo puntualiza Villarespe-Reyes y Sosa Ferreira (2008), aunque la pobreza haya existido desde hace siglos, su concepción y contenido han cambiado de acuerdo a los procesos y mecanismos de cohesión social que operan en cada momento del desarrollo social y, en consecuencia, las acciones para atenderla también. En realidad, es la solución de esos problemas públicos y el grado de satisfacción que genera a la ciudadanía, la que permite comprender la esencia, el fundamento y la ontología no solamente de las acciones de los diferentes actores (gobierno, sociedad civil, academia, sector privado...), sino y, sobre todo, de las decisiones que han precedido esas acciones (Mballa, 2017b).

\section{Zacatecas y los avatares del sector agropecuario: predominancia de una estructura económica tradicional}

Zacatecas tiene una extensión territorial de 75,284, lo cual representa $3.8 \%$ del territorio nacional. Sus coordenadas extremas son $25^{\circ} 09^{\prime}$ al norte, $21^{\circ} 04^{\prime}$ al sur de latitud norte; al este $100^{\circ} 49^{\prime}$ y al oeste $104^{\circ} 19^{\prime}$ de longitud oeste. Colinda al norte con el estado de Coahuila, al noroeste con el estado de Durango, al oeste con el estado de Nayarit, al este con los estados de San Luis Potosí y Nuevo León y al sur, con los estados de Jalisco, Aguascalientes y Guanajuato. Tiene una población aproximativa de 1,490,668, habitantes; lo cual representa $1.3 \%$ de la población nacional, ubicándose en la $25^{\circ}$ entidad más poblada de México (Concanaco, 2014). Está conformado por 58 municipios, como lo indica el mapa 1.

Zacatecas revistió una importancia económica de primer orden en la época colonial, producto de su legendaria riqueza minera, por lo que se 


\section{Mapa 1 \\ Estado de Zacatecas con división política por municipios}

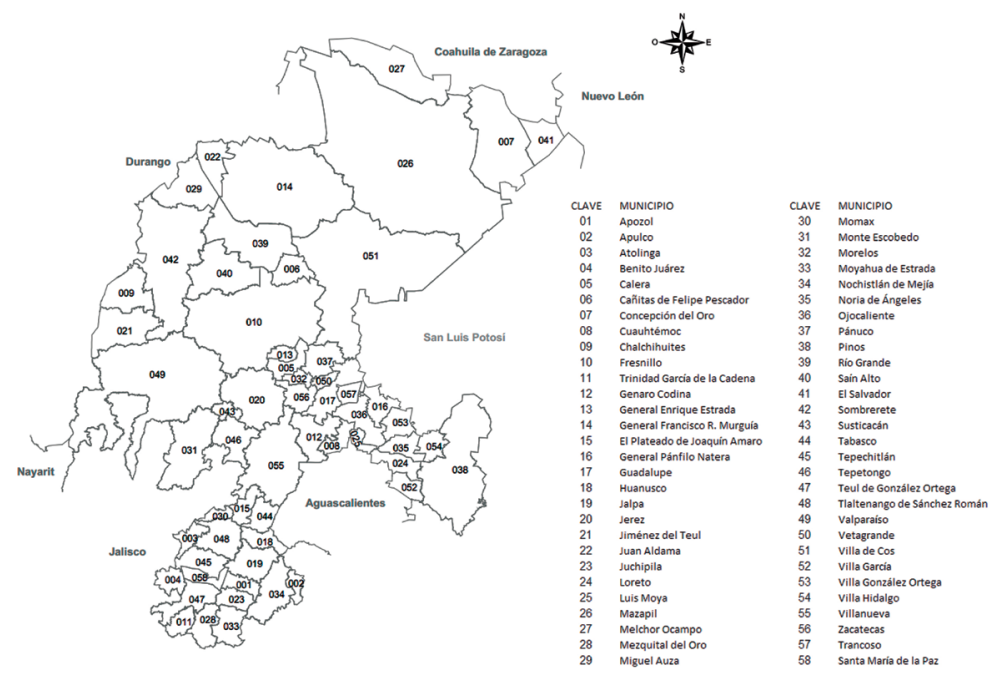

Fuente: Inegi (2005).

convirtió en una de las principales fuentes de tributo para la Corona española. Sin embargo, a partir del siglo XIX, el estado ha sido un actor secundario y marginado de los grandes procesos económicos que ha vivido México (Arnaut y Giorguli, 2010 y Vittrup-Christensen, 2016). De este modo, la combinación de diversos factores propios de la entidad, aunados al carácter territorialmente concentrador de los patrones de desarrollo aplicados en el país, han propiciado una situación adversa para el desarrollo del sector agropecuario. En zacatecas, este sector se ha caracterizado por un escaso dinamismo e innovación, con una especialización en actividades de bajo rendimiento, la escasa remuneración de los trabajadores y una marcada incapacidad para generar empleos (Sagarpa, 2010).

Hoy por hoy, la estructura económica zacatecana es marcadamente tradicional, donde las actividades primarias y extractivas representan una parte importante del empleo y la producción, en comparación con la composición económica del país; sin embargo, estas actividades aportan muy poco al crecimiento y desarrollo del estado. En la gráfica 2 se muestra la aportación de cada municipio en materia del Valor Agregado Bruto, que es una aproximación al cálculo del Producto Interno Bruto municipal (Plan Estatal de Desarrollo, 2011-2016). 


\section{Gráfica 2}

Valor Agregado Bruto per cápita por municipio (Zacatecas, 2009)

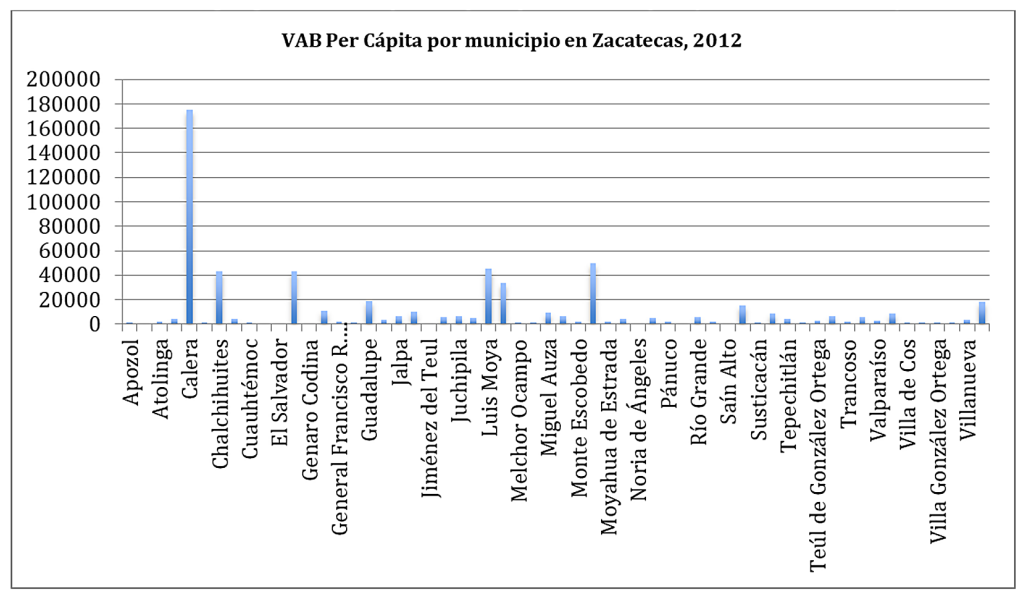

Fuente: elaboración propia con datos del Inegi, 2011.

En Zacatecas, según datos de Inegi (2014), los municipios con un Valor Agregado Bruto más alto son Calera, Sombrerete y Zacatecas. Calera muestra un alto $\mathrm{VAB}$ en materia de manufacturas, por ser un municipio ubicado en medio de la zona industrial del estado. Sombrerete es un municipio minero y su VAB está fuertemente compuesto por este sector. El sector turismo aporta al municipio de Zacatecas gran parte de su VAB. Noria de Ángeles, El Plateado de Joaquín Amaro y Apulco se encuentran entre los municipios con menor VAB. De igual forma, se presentan fuertes rezagos en materia de productividad y competitividad de la mayoría de los sectores; esto se debe a factores como infraestructura deficiente, rezago tecnológico, reducido tamaño de las unidades económicas y especialización regional en ramas productivas de bajo valor agregado.

A pesar de ese sombrío panorama, las actividades agropecuarias constituyen un sector productivo muy importante para la mayoría de los municipios que conforman la entidad. La actividad agrícola se desarrolla en alrededor de 1.13 millones de hectáreas, que representan casi $6 \%$ de la superficie cultivada en el país. Dicha labor genera una producción cuyo valor es actualmente de poco más de 10 mil millones de pesos. Sólo 12.7\% de la superficie cultivada en el Estado cuenta con riego, producto principalmente de la escasez de agua en la mayor parte del territorio estatal. En cuanto a la orientación de la actividad, continúan predominando los granos básicos, especialmente el frijol, cultivo al que se dedica 39\% de la superficie, seguido del maíz grano con $23 \%$. Les siguen en importancia la avena forrajera, el trigo, el chile verde y la cebada grano (Inegi, 2014). 
Para 2012, la economía zacatecana medida por su Producto Interno Bruto anual, ascendió a 123 mil 430 millones de pesos corrientes, cifra que representa aproximadamente $1.0 \%$ de la economía nacional, ubicándose como el quinto estado con menor PIB. En lo que se refiere al dinamismo económico en los últimos años, Zacatecas ha presentado un crecimiento promedio cercano a $4 \%$ que, si bien es mayor al promedio nacional, resulta insuficiente para mejorar las condiciones socioeconómicas de la población y generar los empleos requeridos (Sánchez-Toledano et al., 2013).

En efecto, la economía se caracterizó por una caída en el sector secundario (construcción y manufacturas), estancamiento de las actividades agrícolas y avance marginal de algunas actividades terciarias. Sin embargo, la recuperación de los ingresos por remesas del extranjero en la entidad $2.6 \%$ contribuyó a compensar parcialmente el bajo crecimiento del empleo formal en la entidad (Monreal, 2013). Como consecuencia de ello, en el Informe de Pobreza y Evaluación de Zacatecas 2012, Coneval (2012) concluye que con respecto de las 32 entidades federativas, Zacatecas ocupó el lugar seis en porcentaje de población en pobreza y el lugar 12 en porcentaje de población en pobreza extrema. Por lo tanto, se ubica dentro de las 10 entidades con mayor pobreza y hambre en el país. La gráfica 3 muestra datos sobre la pobreza en Zacatecas en 2012.

\section{Gráfica 3}

\section{Población en pobreza en Zacatecas 2012}

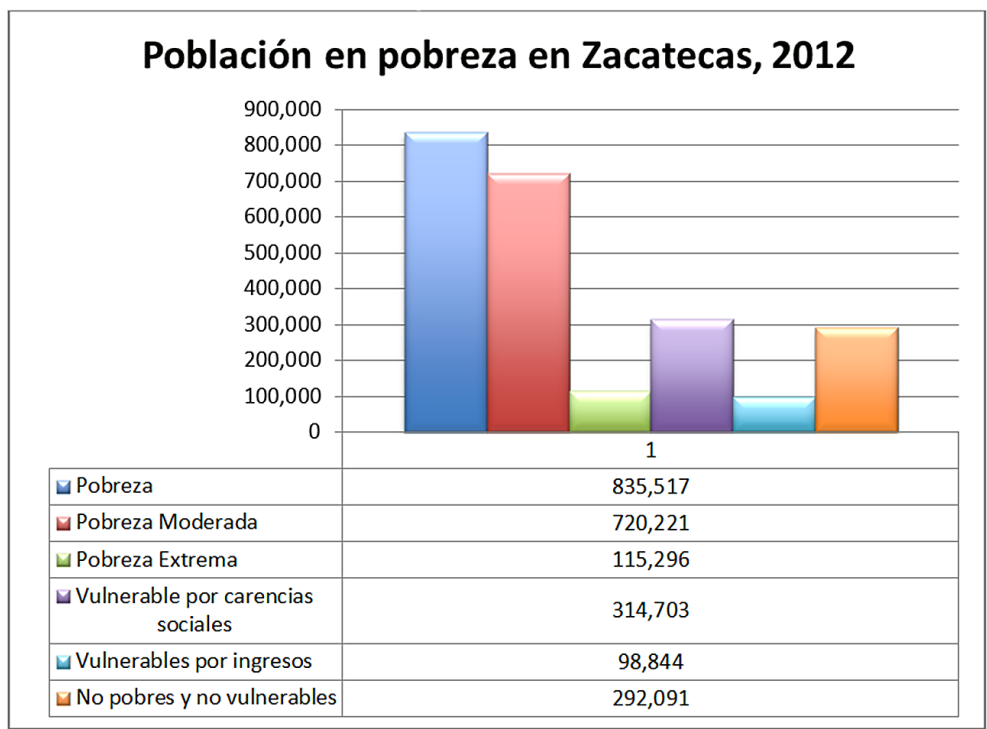

Fuente: elaboración propia con datos de Coneval, 2012. 
Según esta gráfica, en 2012 del total de la población que habitaba el estado, $54.2 \%$ se encontraba en situación de pobreza; es decir, 835,517 personas de un total de 1,541,155 tuvieron al menos una carencia social y no tuvieron ingresos suficientes para satisfacer sus necesidades básicas. Del total de la población, $7.5 \%$ se encontraba en pobreza extrema, lo que significa que 115,296 personas tuvieron al menos tres carencias sociales y no tuvieron un ingreso suficiente para adquirir una canasta alimentaria. Del total de la población, $60.6 \%$ cuenta con un ingreso menor a la línea de bienestar y $30.3 \%$ con un ingreso inferior a la línea de bienestar mínimo.3 A nivel municipal, ese mismo informe indica los municipios con mayor porcentaje de población en situación de pobreza extrema repartido de la siguiente forma: 1 . Fresnillo, 118,352 personas (56.1\%); 2. Pinos, 58,628 personas $(73.0 \%)$; 3. Guadalupe, 50,935 personas (34.7\%); 4. Sombrerete, 38,423 personas $(62.5 \%)$ y 5 . Río Grande, 38,209 personas (62.9\%) (Coneval, 2012).

Como se observa, destacan varias incongruencias en el sector agropecuario en Zacatecas, con una clara predominancia de una estructura económica tradicional. Asimismo, independientemente de su temporalidad, estos datos constituyen una buena base para entablar un análisis del hambre en el estado de Zacatecas bajo el modelo de Mínimos Cuadrados Ordinarios.

\section{Marco metodológico: Procedimiento del modelo por Mínimos Cuadrados Ordinarios}

De acuerdo con Hanke y Wichern (2006), el procedimiento para el uso del MCO consiste en minimizar la suma de los cuadrados de las distancias verticales entre los valores de los datos y los de la regresión estimada, es decir, minimizar la suma de los residuos al cuadrado, teniendo como residuo la diferencia entre los datos observados y los valores del modelo.

Dado un conjunto $n$ de parejas ( $x i, y i)$ de datos, se debe encontrar la ecuación de la recta $y=a x+b$ que pasa lo más cerca posible de los puntos experimentales (de forma que éstos se repartan uniformemente alrededor de la recta). En este sentido, el método del ajuste por mínimos cuadrados o regresión lineal permite obtener la pendiente $a$ de la recta y la ordenada $b$ en el origen, correspondientes a la recta $y=a x+b$ que

${ }^{3}$ La medición de pobreza utiliza dos líneas de ingreso: la línea de bienestar mínimo, que equivale al valor de la canasta alimentaria por persona al mes; y la línea de bienestar, que equivale al valor total de la canasta alimentaria y de la canasta no alimentaria por persona al mes. Para actualizar mensualmente las líneas de bienestar mínimo y bienestar, el Coneval toma en cuenta los cambios del valor de las canastas alimentaria y no alimentaria utilizando el Índice Nacional de Precios al Consumidor (INPC) calculado y publicado por el Inegi (Coneval, 2016). 
mejor se ajusta a los $n$ datos $(x i, y i)$; es decir, permite establecer una relación funcional entre dos variables; donde $x$ es la variable independiente e $y$ es la variable independiente.

Dada una muestra aleatoria, con el Método de Mínimos Cuadrados Ordinarios (MCO), se estiman los parámetros de la pendiente y la intercepción del modelo poblacional. Según Wooldridge (2010), con la línea de regresión de los MCO se obtiene el cambio pronosticado en la variable dependiente $(y)$ para un determinado cambio en las independientes $(x 1$. $x 2, \ldots x k)$ El análisis de regresión múltiple es más adecuado para un análisis Ceteris Paribus debido a que permite controlar de manera explícita muchos otros factores que afectan en forma simultánea a la variable dependiente. Esto es importante tanto para probar teorías económicas como para evaluar los efectos que pueden tener esas teorías en la realidad social, es decir, cuando hay que apoyarse en datos no experimentales. Sin embargo, hay que reconocer que debido a que los modelos de regresión múltiple pueden admitir diversas variables explicativas que tal vez estén correlacionadas, puede esperarse una inferencia casual en casos en los que el análisis de regresión simple podría no dar buenos resultados.

$\mathrm{Si}$ al modelo se le agregan factores que pueden ser útiles para explicar $y$, entonces puede explicarse más de la variación en $y$. Por tanto, el análisis de regresión múltiple puede emplearse para construir mejores modelos para predecir la variable dependiente. Otra ventaja del análisis de regresión múltiple es que puede incorporar relaciones con formas funcionales muy generales. En el modelo de regresión simple, en la ecuación únicamente puede aparecer una función de una sola variable explicativa.

El modelo de regresión múltiple sigue siendo el vehículo más empleado para el análisis empírico en la economía y en otras ciencias sociales. Asimismo, el MCO se usa de manera general para estimar los parámetros del modelo de regresión múltiple (Wooldridge, 2010).

Con base a ese planteamiento, el modelo general de regresión lineal múltiple puede expresarse de la forma siguiente:

$$
y=\beta_{0}+\beta_{1} x_{1}+\beta_{2} x_{2}+\ldots+\beta_{n} x_{i}+\varepsilon_{t}
$$

En (1):

$\beta_{0}$ es el intercepto

$\beta_{1}$ es el parámetro asociado con

$\beta_{2}$ es el parámetro asociado con $x_{2}$. Y así sucesivamente.

La variable " $\varepsilon_{t}$ ” es el término de error o perturbación. Este término contiene los otros factores distintos de $x_{1}, x_{2}, \ldots, x_{i}$, que afectan a " $y$ ". 
No importa cuántas variables explicativas se incluyan en el modelo, siempre habrá factores que no se pueden incluir y todos ellos juntos están contenidos en $\varepsilon_{t}$ (Wooldridge, 2010).

\section{Resultados: El análisis de la situación de hambre con base en el MCO en el estado de Zacatecas}

El conjunto de datos o variables que se tomaron en cuenta para la caracterización del modelo en este artículo fueron los siguientes:

Promedio de años de escolaridad. La relación es Escolaridad-Ingreso. Una relación contundente que existe entre los años de escolaridad, entre más años de escolaridad se tengan mayor probabilidad de encontrar un trabajo mejor remunerado, y por ende menos probabilidad de padecer hambre. El dato se tomó de un informe realizado por la Sedesol en conjunto con el Coneval, donde se muestran los ańos de escolaridad en promedio de la población de cada municipio.

Promedio de habitantes por vivienda. Se considera que esta variable es de suma importancia y que se relaciona directamente con el hambre, pues como los estudios de la pobreza del Coneval lo indican, las familias más numerosas tienden a ser de las más pobres.

Valor Agregado Bruto (VAB) per cápita. Debido a la inexistencia de datos sobre el Producto Interno Bruto municipal en el estado de Zacatecas se calculó el Valor Agregado Bruto Total de la base de datos del Inegi, 2010, "Censo económico 2010"; para construirlo se sumaron las cifras totales las 18 actividades económicas que el Inegi contabiliza: agricultura, cría y explotación de animales, aprovechamiento forestal, pesca y caza, minería, generación de energía, agua y gas, construcción, industria manufacturera, comercio, transporte, información, y todos los servicios, de cada uno de los municipios del estado de Zacatecas. Al obtener la cifra se dividió entre el total de la población de cada municipio y se obtuvo el Valor Agregado Bruto Total Per Cápita, medido en pesos mexicanos.

Hectáreas cosechadas: Se consideró esta variable porque el estado de Zacatecas es un estado rural, donde una cantidad considerable de la población aún se dedica a este tipo de actividades. Está medida en hectáreas.

Porcentaje de población con Hambre, que se mide con el modelo. Las cifras son el porcentaje de gente con carencia alimenticia con respecto al total de la población del municipio. 
Producto Interno Bruto (PIB) municipal estimado: Para incorporar esta variable, los datos del PIB fueron tomados de una investigación realizada por González-Estrada y Gallegos-Cedillo (2014) con el título "El producto interno bruto de los municipios de México: II. Estados M-Z” en la Revista Mexicana de Ciencias Agricolas. Dicha investigación propone un método no-paramétrico para obtener los estimadores del Producto Interno Bruto (PIB) de los municipios de la república mexicana en su totalidad y por actividad económica.

Población Económica Activa (PEA) con alguna ocupación: Para obtener informacion sobre la población económica activa en Zacatecas, se recabó informacion de Inegi en un documento titulado "Censos y conteos de población y vivienda". 


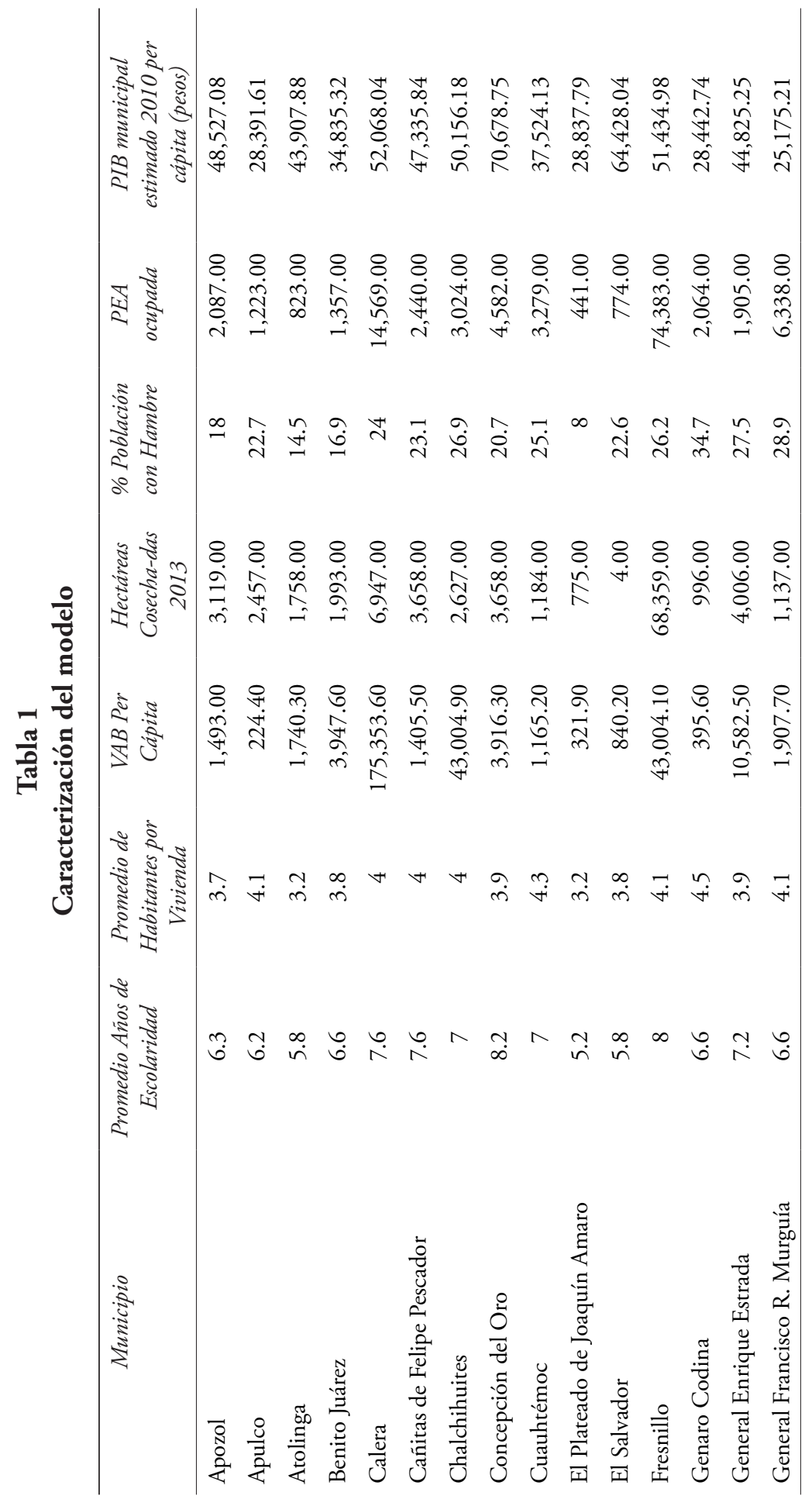




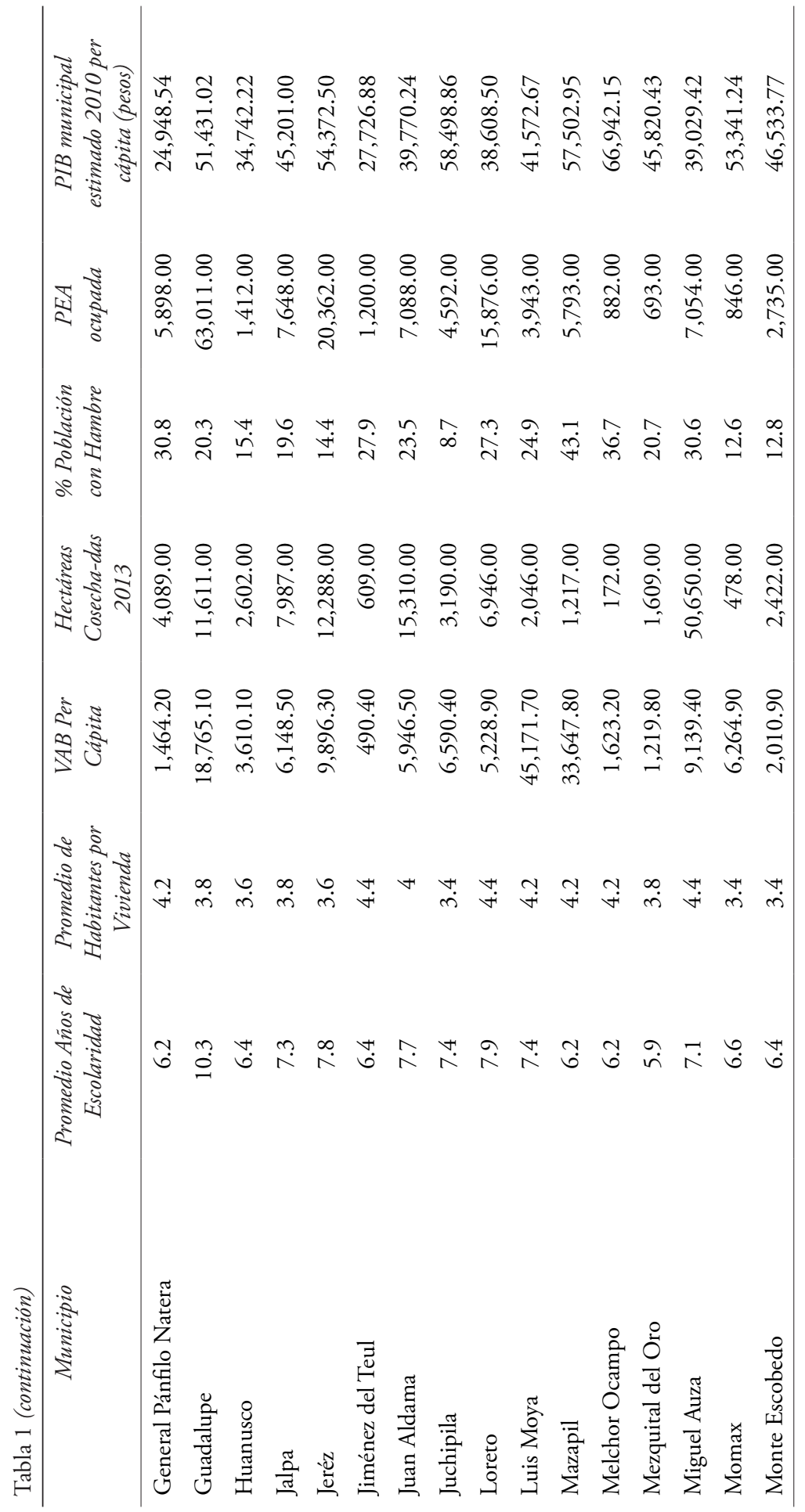




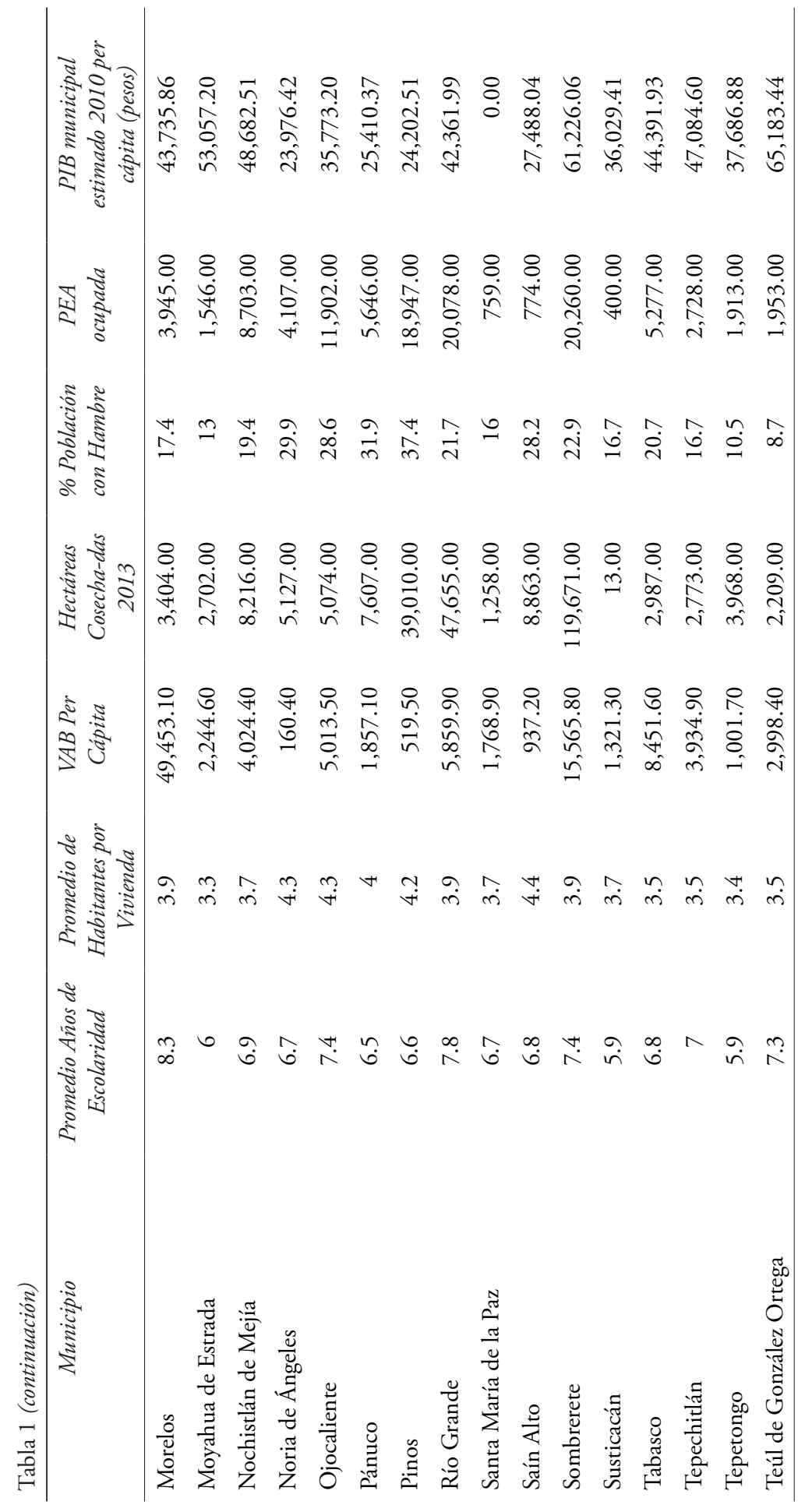




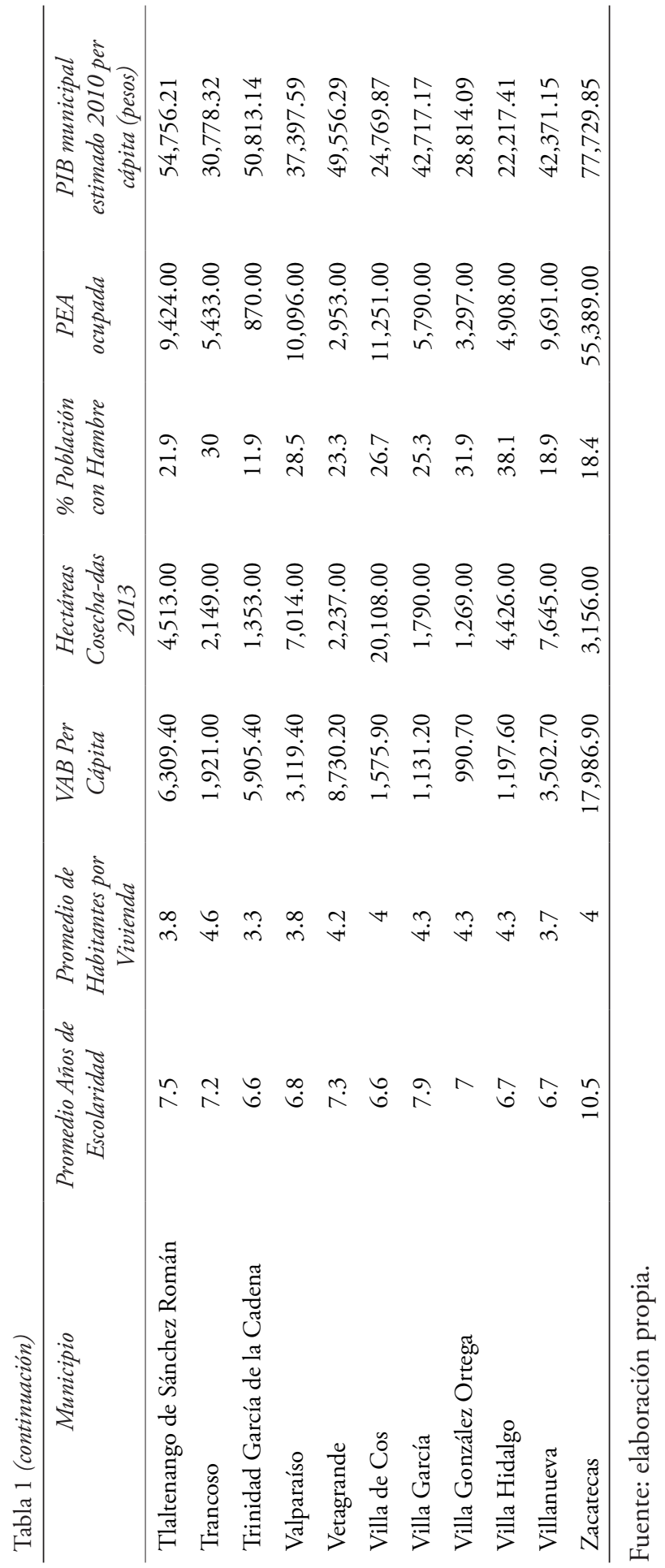




\section{Análisis econométrico con el MCO}

Como se mencionó, el método utilizado se enfocó en la estimación de un modelo de regresión lineal múltiple por los MCO donde:

$y=\beta_{0}+\beta_{1}$ años de escolaridad $+\beta_{2}$ habitantes por vivienda $+\beta_{3} V A B+\beta_{4}$ hectáreas cosechadas $+\beta_{5}$ PIB municipal $+\beta_{6}$ PEA ocupada $+\varepsilon_{t}$

En (2):

$y$ es el parámetro asociado a la variable hambre.

$\beta_{0}$ es el intercepto.

$\beta_{1}$ es el parámetro asociado a la variable Promedio Años de Escolaridad. $\beta_{2}$ es el parámetro asociado a la variable Habitantes por Vivienda.

$\beta_{3}$ es el parámetro asociado a la variable Valor Agregado Bruto.

$\beta_{4}$ es el parámetro asociado a la variable Hectáreas Cosechadas.

$\beta_{5}$ es el parámetro asociado a la variable PEA ocupada.

$\beta_{6}$ es el parámetro asociado a la variable PIB municipal.

El modelo se aproxima a la satisfacción de los supuestos clave en el MCO. En la tabla 2 siguiente se muestran los resultados obtenidos del modelo Mínimos Cuadrados Ordinarios, usando el programa estadístico para computadora "Gretl”.

Contraste de normalidad de los residuos -

Hipótesis nula: el error se distribuye normalmente

Estadístico de contraste: Chi-cuadrado $(2)=0.147696$; con valor $\mathrm{p}=$ 0.928813

$\mathrm{La}$ (l) indica el uso de logaritmo para cada variable

Contraste de especificación RESET -

Hipótesis nula: La especificación es adecuada

Estadístico de contraste: $\mathrm{F}(2,48)=1.64306$; con valor $\mathrm{p}=\mathrm{P}(\mathrm{F}(2,48)>$ $1.64306)=0.204077$

De la tabla (2), se construye la ecuación (3) donde se toman los valores de los coeficientes y se asocian a sus variables.

hambre : -.0861412-1.31168 Años de escolaridad +3.75753 Habitantes por vivienda +0.031340 VAB per cápita- 0120103 hectáreas cosechada +0.10343 PEA ocupada +.0319442 PIB municipal $+\varepsilon_{t}$ 
Tabla 2

Modelo 1: MCO, usando las observaciones 1-58 ( $n=57)$. Variable dependiente: Población con Hambre

\begin{tabular}{|c|c|c|c|c|c|}
\hline & Coeficiente & Desv. Típica & Estadistico $t$ & Valorp & \\
\hline Variable & -0.861412 & 1.28027 & -0.6728 & 0.5041 & \\
\hline 1 Años de Escolaridad & -1.31168 & 0.317646 & -4.1294 & 0.0001 & $* * *$ \\
\hline 1 Habitantes por Vivienda & 3.75753 & 0.317866 & 11.8211 & $<0.0001$ & $* * *$ \\
\hline 1 VAB Per Cápita & 0.0313403 & 0.0231851 & 1.3517 & 0.1825 & \\
\hline 1 Hectareas Cosechadas 2013 & -0.0120103 & 0.0201998 & -0.5946 & 0.5548 & \\
\hline 1 PEA ocupada & 0.10343 & 0.0359321 & 2.8785 & 0.0059 & $* * *$ \\
\hline 1 PIB per cápita & 0.0319442 & 0.114852 & 0.2781 & 0.7821 & \\
\hline Media de la variable. dependiente. & 3.067188 & \multicolumn{2}{|c|}{ D.T. de la vble. dep. } & \multicolumn{2}{|c|}{0.383053} \\
\hline Suma de cuad. residuos & 1.483026 & \multicolumn{2}{|c|}{ D.T. de la regresión } & \multicolumn{2}{|c|}{0.172222} \\
\hline R-cuadrado & 0.819515 & \multicolumn{2}{|c|}{ R-cuadrado corregido } & \multicolumn{2}{|c|}{0.797856} \\
\hline $\mathrm{F}(6,50)$ & 37.83844 & \multicolumn{2}{|c|}{ Valor p (de F) } & \multicolumn{2}{|c|}{$6.18 \mathrm{e}-17$} \\
\hline Log-verosimilitud & 23.11605 & \multicolumn{2}{|c|}{ Criterio de Akaike } & \multicolumn{2}{|c|}{-32.23209} \\
\hline Criterio de Schwarz & -17.93073 & \multicolumn{2}{|c|}{ Crit. de Hannan-Quinn } & \multicolumn{2}{|c|}{-26.67409} \\
\hline
\end{tabular}

Fuente: elaboración propia

En (3) el intercepto $\beta_{0}$ es el valor predicho para $\widehat{\text { hambre }}$ cuando todas las variables son igual a cero. Es decir, en caso de que la variable constante fuera significativa y todas las demás variables (explicativas) tuvieran un valor igual a cero la población con hambre sería de -.0861412. Dado que no puede haber una población en negativo, el intercepto no tiene en sí ningún significado.

Estimaciones más interesantes son las que arrojan los coeficientes "promedio de habitantes por vivienda y promedio de años de escolaridad". Como era de esperarse, existe una relación parcial positiva entre el número de habitantes por vivienda y el porcentaje de personas con hambre; la interpretación es que con las variables: años de escolaridad, VAB per cápita, hectáreas cosechadas, PIB municipal y PEA ocupada, constantes (Ceteris Paribus), cada punto más en habitantes por vivienda, o sea cada habitante agregado a la vivienda, aumenta en 3.75 unidades el porcentaje de personas con hambre.

Es decir, si se eligen dos municipios, A y B, y éstos tienen el mismo promedio de años de escolaridad, mismo VAB, mismas hectáreas cosechadas, igual PIB municipal e igual PEA ocupada, pero en A habita en promedio una persona más en la vivienda, que en $B$, se predice que en el municipio A puede haber 3.75\% más hambre que en municipio $\mathrm{B}$. Los 
tres asteriscos en el $p$ value en este parámetro estimado indican que la variable es al $99 \%$ significativa, lo que quiere decir que explica de una manera efectiva al hambre como la variable dependiente considerada en el estudio.

El signo de ańos de escolaridad, implica que con Ceteris Paribus, un cambio de un punto en años de escolaridad tendrá un efecto de -1.3 sobre el porcentaje de población con hambre. Se predice que un año más de educación disminuye la probabilidad de hambre en $3.33 \%$. Lo que concuerda con la teoría descrita anteriormente, donde se estipula que la población con mayor escolaridad tiene mayor probabilidad de obtener un trabajo mejor remunerado y por ende, su probabilidad de tener carencia alimenticia es menor. Al igual que en parámetro estimado "habitantes por vivienda", el parámetro estimado asociado a ańos de escolaridad tiene una significancia de $99 \%$ en el valor de la variable dependiente, es decir que esta variable explica de una forma muy convincente a la variable que se está tratando de estudiar.

El valor estimado para la variable hectáreas cosechadas con Ceteris Paribus arroja un valor de -0.0120103 . En caso de que esta variable fuera significativa (la cual no lo es debido al $p$ value), indicaría que una vez que se haya tomado en cuenta el número de habitantes por vivienda, ańos de escolaridad, el VAB y las hectáreas cosechadas, una hectárea más cosechada en el estado de Zacatecas, reduciría el hambre en $0.0120 \%$. Sin embargo, esta variable no tiene gran significancia. El valor $p$ no es significativo, como puede ser corroborado en la tabla 1.

La variable Población Económicamente Activa Ocupada (PEA ocupada) tiene un valor de 0.103 . Lo que resultado indica es que, al variar en $1 \%$ la PEA ocupada, el hambre fluctua en $0.103 \%$. Esta variable no es significativa a la hora de la explicación de la variable dependiente; quizás, se puede justificar por aspectos como el hacinamiento o que actualmente los jóvenes vivan más tiempo en las casas de sus padres. Estos elementos se relacionan estrechamente con el ingreso, lo cual significa que la vivienda y sus espacios, generalmente, se configuran como un espejo del ingreso.

El PIB es una variable macroeconómica que expresa el valor monetario de la producción de bienes y servicios de demanda final de un país o región durante un periodo determinado, normalmente de un año. En cuanto al PIB municipal per cápita en Zacatecas, el modelo arrojó un valor del coeficiente de 0.0319442 con un $p$ value poco significativo. Sin embargo, en caso que éste fuera significativo, lo que el modelo nos está diciendo es que las variaciones en el PIB influyen en la población con hambre en valor del orden de $0.031 \%$. Sin embargo, es necesario comentar que el PIB per cápita no retrata la verdadera distribución del ingreso, 
al no reflejar la riqueza real de las familias y de las personas que viven en las casas.

\section{Conclusiones}

Después de este recorrido, el MCO nos indica que cuando se habla de análisis de una problemática como la del hambre, es necesario no sólo mirar su proceso global y sus características esenciales, sino también indagar las formas singulares como se involucran las demás dimensiones susceptibles de generarlo. Dicha tendencia abre el telón para la consideración de la multifactorialidad/multidimensionalidad como germen de cualquier problema público.

Asimismo, se observa que los resultados arrojados por el modelo son contundentes en términos epistemólogos. Concuerdan con los objetivos planteados. Tomando en cuenta las variables independientes del modelo econométrico construido, se observa que el número de habitantes por vivienda es el factor más importante al momento de determinar la probabilidad de padecer hambre. Es cierto que esta conclusión no requiere de comprobaciones de matemáticas; sin embargo, incluye de manera implícita e inductiva, el impacto de los subsidios y transferencias directas, que precisamente están vinculadas al número de habitantes de las familias en situación de pobreza y de carencia alimentaria.

$\mathrm{Al}$ ser Zacatecas un estado marginado, poco industrializado y en desventaja frente a los demás de la republica mexicana, este análisis nos advierte que el aumento de un habitante en la vivienda, incrementa considerablemente la posibilidad de padecer hambre en el mismo. De igual manera, los resultados muestran que un ańo más invertido en formación académica de una población es susceptible de disminuir la probabilidad de que ésta padezca carencia alimenticia. Por lo que se puede decir que la inversión en la educación es uno de los mejores mecanismos a largo plazo para combatir este problema. La tierra es un tema aparte, a pesar de que el estado Zacatecas sea líder en la producción de algunos productos básicos para lo hogares mexicanos, esta producción no aporta una cantidad considerable al PIB estatal ni nacional, y como se comprueba con el modelo, no tiene significancia sobre la variable estudiada.

Finalmente las variables Producto Interno Bruto, Valor Agregado Bruto y Población Económicamente Activa ocupada muestran resultados poco significativos, lo que evidencia que el hambre es un problema de alta complejidad que necesita ser estudiado desde diferentes enfoques. El gran desafío aquí es tener la capacidad de relacionar todos los elementos susceptibles de explicar los avatares del padecimiento del hambre en una 
población, ya que la carencia alimenticia es un problema derivado del complejo fenómeno de la pobreza. En este sentido, el análisis del hambre estudio desde un modelo matemático, tiene que ir de la mano con muchos más estudios cualitativos que ayuden a entender esta realidad social. En este sentido, compartimos la idea de Bardach (1998), según la cual el análisis de cualquier problemática social, es más un arte que una ciencia, se basa tanto en la intuición como en el método; es la manera como se utiliza el conocimiento desde una perspectiva multidisciplinaria, para descifrar los enigmas y complejidades de los problemas sociales.

Para concluir este artículo, pensamos que una concepción del hambre desde su complejidad, obliga a abordarlo de manera integral a partir de los enfoques de subsistencia, de necesidades básicas y de capacidades, entre otros. A través del enfoque de subsistencia, es necesario centrar el análisis en la dimensión distributiva de los recursos; con respecto a la perspectiva de las necesidades básicas, centrar la atención en sus manifestaciones y en cuanto al enfoque de las capacidades, incorporar la explicación estructural de las causas, los alcances, los efectos y las consecuencias del hambre. Este planteamiento significa que, más allá de las dimensiones espaciotemporales, la aplicación de la regresión lineal es susceptible de generar información útil, quizás no tanto por el resultado en términos matemáticos, sino por el análisis de las diferentes variables tomadas en cuenta.

\section{Fuentes consultadas}

Acosta-Acosta, Guillermo Alejandro (2017), La seguridad alimentaria en México y su problemática en el contexto del desarrollo, Instituto de Investigaciones Estratégicas de la Armada de México, Ciudad de México, México.

Arámbula-Reyes, Alma (2008), “Tratados Comerciales de México”, Cámara de Diputados Centro de Documentación, Información y Análisis, Ciudad de México, México, <http://www.diputados. gob.mx/sedia/sia/spe/SPE-ISS-05-08.pdf>, 12 de marzo de 2017.

Argueta-Mondragón, Roger y Julián Carrazón-Alocén (2014), Hambre de saber, saber de hambre: los programas PESA de Centroamérica, quince años de cooperación para la seguridad alimentaria y nutricional, Organización de las Naciones Unidas para la Alimentación y la Agricultura, Madrid, España. 
Arnaut, Alberto y Silvia Giorguli (2010), Los grandes problemas de México, El Colegio de México, Ciudad de México, México.

Bardach, Eugene (1998), Los ocho pasos para el análisis Politicas Públicas: Un manual para la práctica, Centro de Investigación y Docencia Económicas, Ciudad de México, México.

Becker, Gary (1995), "Human capital and poverty alleviation. HRO", working paper núm. 52, The World Bank, Washington, Estados Unidos de América.

Calderón-Salazar, Jorge Alfonso (2014), 20 años de TLCAN: su impacto en la balanza de pagos, agricultura y vulnerabilidad externa de la economía mexicana, Miguel Ángel Porrúa, Ciudad de México, México.

Castro, Juan (2016), "Hay 850 mil pobres en Zacatecas: Coneval”, El Sol de Zacatecas, 24 de octubre, Organización Editorial Mexicana, Zacatecas, México, <https:/www.elsoldezacatecas.com.mx/ finanzas-locales/hay-850-mil-pobres-en-zacatecas-coneval>, 17 de noviembre de 2017.

Ceja-Mena, Concepción (2004), "La política social mexicana de cara a la pobreza”, Scripta Nova-Revista Electrónica de Geografía y Ciencias Sociales, VIII (176), Universidad de Barcelona, Barcelona, España, pp. 2-16.

Chávez, Héctor (2014), "Dependencia agroalimentaria pasó del 10 al $43 \%$ en 20 años", El Financiero, 28 de octubre, Ciudad de México, México, <http://www.elfinanciero.com.mx/economia/dependencia-agroalimentaria-paso-del-10-al-43-en-20-anos.html>, 29 de noviembre 2017.

Coneval (Consejo Nacional de Evaluación de la Política de Desarrollo Social) (2017), Coneval informa la evolución de la pobreza 20102016, Consejo Nacional de Evaluación de la Política de Desarrollo Social, Ciudad de México, México.

Coneval (Consejo Nacional de Evaluación de la Política de Desarrollo Social) (2016), Resultados de pobreza en México 2016 a nivel nacional y por entidades federativas, Consejo Nacional de Evalua- 
ción de la Política de Desarrollo Social, Ciudad de México, México.

Coneval (Consejo Nacional de Evaluación de la Política de Desarrollo Social) (2015), Información de pobreza y evaluación en las entidades federativas, Consejo Nacional de Evaluación de la Política de Desarrollo Social, Zacatecas, México.

Coneval (Consejo Nacional de Evaluación de la Política de Desarrollo Social) (2014), Resultados de pobreza en México 2014 a nivel nacional y por entidades federativas, Consejo Nacional de Evaluación de la Política de Desarrollo Social, Ciudad de México, México.

Coneval (Consejo Nacional de Evaluación de la Política de Desarrollo Social) (2012), Informe de pobreza y evaluación en el estado de Zacatecas, 2012, Consejo Nacional de Evaluación de la Política de Desarrollo Social, Ciudad de México, México.

Concanaco (Confederación de Cámaras Nacionales de Comercio, Servicios y Turismo) (2014), Indicadores económicos del estado de Zacatecas, Confederación de Cámaras Nacionales de Comercio, Servicios y Turismo, Ciudad de México, México, <http://www. concanaco.com.mx/documentos/indicadores-estados/Zacatecas. pdf>, 28 de agosto de 2016.

Crawford, Terry (2011), "Impacto del TLCAN en el comercio agrícola", Revista Mexicana de Agronegocios, núm. 28, Sociedad Mexicana de Administración Agropecuaria A.C., Torreón, México, pp. 457-468.

FAO (Organización de las Naciones Unidas para la Alimentación y la Agricultura) (2017), América Latina y el Caribe se alejan de la meta del Hambre Cero en 2030, Organización de las Naciones Unidas para la Alimentación y la Agricultura, Santiago de Chile, Chile, <http://www.fao.org/news/story/es/item/1043137/>, 29 de noviembre de 2017.

Flores-Alonso, María de Lourdes (2012), La medición de la pobreza en México, Centro de Estudios Sociales y de Opinión Pública, Ciudad de México, México. 
Flores-Payan, Lucio e Iván Alejandro Salas-Durazo (2018), "Calidad del empleo en grupos socialmente vulnerables en México. El caso de los adultos mayores", Economía, Sociedad y Territorio, XVIII (56), El Colegio Mexiquense A. C., Toluca, México, pp. 1-33.

Food Secure Canada (2012), "The six pillars of food sovereignty”, usccanada.org, Nyéléni, Canadá, <http://usc-canada.org/UserFiles/ File/SixPillars_Nyeleni.pdf>, 25 de julio 2016.

González-Estrada, Adrián y Gilberto Gallegos-Cedillo (2014), "El producto interno bruto de los municipios de México: II. Estados M-Z”, Revista Mexicana de Ciencias Agricolas, V (8), Instituto Nacional de Investigaciones Forestales, Agrícolas y Pecuarias, Ciudad de México, México, pp. 1405-1421.

Hanke, John y Dean Wichern (2006), Pronósticos en los negocios, Pearson, Ciudad de México, México.

Ibarra-Cortés, Mario Eduardo y Louis Valentin Mballa (2017), Complexité et défis de la gestión des municpalités au Mexique, Publibook, París, Francia.

Inegi (Instituto Nacional de Estadística y Geografía) (2014), Anuario estadístico y geográfico de Zacatecas, Instituto Nacional de Estadística y Geografía, Aguascalientes, México.

Inegi (Instituto Nacional de Estadística y Geografía) (2011), Perspectivas estadísticas: Zacatecas, Instituto Nacional de Estadística y Geografía, Aguascalientes, México.

Inegi (Instituto Nacional de Estadística y Geografía) (2010), Censos y conteos de población y vivienda, Instituto Nacional de Estadística y Geografía, Aguascalientes, México.

Inegi (Instituto Nacional de Estadística Geografía) (2005), Marco Geoestadistico Municipal 2005, Instituto Nacional de Estadística Geografía, Aguascalientes, México.

Kuntz-Ficker, Sandra (2010), Historia económica general de México: de la Colonia a nuestros días, El Colegio de México, Ciudad de México, México. 
Levy, Carlos (2009), "Crisis y retos de la Política Exterior de México: 2006-2012", Revista Mexicana de Ciencias Politicas y Sociales, LI (205), Universidad Nacional Autónoma de México, Ciudad de México, México, pp. 119-141.

López-Espinosa, Antonio y Héctor Martínez (2002), “¿Qué es el hambre? Una aproximación conceptual y una propuesta experimental”, Revista Investigación en Salud, IV (1), Centro Universitario de Ciencias de la Salud Guadalajara, Guadalajara, México, pp. 1-15.

Losch, Bruno (2016), "Las agriculturas familiares: en el corazón de la historia de las agriculturas del mundo", en Sourisseau Jean-Michel (ed.), Las agriculturas familiares y los mundos del futuro, Edición IICA y Agencia Francesa para el Desarrollo, San José, Costa Rica, pp. 13-41.

Mballa, Louis Valentin (2017a), "Desarrollo local y microfinanzas como estrategias de atención a las necesidades sociales: un acercamiento teórico conceptual", Revista Mexicana de Ciencias Políticas y Sociales, XII (229), Universidad Nacional Autónoma de México Nueva Época, Ciudad México, México, pp. 101-128.

Mballa, Louis Valentin (2017b), Politicas públicas y complejidad: en búsqueda de soluciones a los problemas públicos, Miguel Ángel Porrúa, Ciudad de México, México.

Mballa, Louis Valentin (2015), "Public Policies as a Government challenge to fight against Poverty in San Luis Potosi”, GE-International Journal of Management, 3 (12), Research Associated Asia Research Foundation, New Delly, Indian, pp. 99- 112.

Mella, José María y Alfonso Mercado (2006), "La economía agropecuaria mexicana y el TLCAN”, Revista Comercio Exterior, 56 (3), Ciudad de México, México, pp. 181-193.

Monreal, Ricardo (2013), "Centenario de la toma de Zacatecas III", multimedia, Ciudad de México, México, <http://ricardomonreal. $\mathrm{mx} /$ centenario-de-la-toma-de-zacatecas-iii/ $>, 4$ de diciembre de 2017.

Moral-Barrera, Laura del y Elena Brenda, Murillo-Villanueva (2015), "La balanza comercial de productos agropecuarios en México en el 
contexto de la dependencia alimentaria, 2010-2015”, Revista Economía Actual, VIII (3), Universidad Autónoma del Estado de México, Toluca, México, pp.16-20.

Moreno-Sáenz, Lucero Ivone, Salvador González-Andrade y Jaime Arturo Matus-Gardea (2016), "Dependencia de México a las importaciones de maíz en la era del TLCAN", Revista Mexicana de Ciencias Agricolas, 7 (1), Instituto Nacional de Investigaciones Forestales, Agrícolas y Pecuarias, Ciudad de México, México, pp. 115-126.

Ochoa, César y Guadalupe Muñoz-Muñoz (2014), "Hambre, apetito y saciedad”, Revista Cubana de Alimentación y Nutrición, 24 (2), Instituto de Nutrición e Higiene de los Alimentos, Habana, Cuba, pp. 268-279.

Ornelas-Delgado, Jaime (2007), "La economía mexicana en el gobierno de Vicente Fox", Aportes, XII (34), Benemérita Universidad de Puebla, Puebla, México, pp. 141-158.

Plan Estatal de Desarrollo (2011- 2016), "Zacatecas hoy", Gobierno del estado de Zacatecas, Zacatecas, México, <http://www.seduzac. gob.mx/portal/documentos/05_zacatecas_hoy.pdf>, 25 de junio de 2016.

Quispe-Cornejo, Silvia (2000), "Geografía del Hambre”, Revista de Investigación Social, IV (5), Instituto de investigaciones Sociales/ Universidad Nacional Autónoma de México, Ciudad de México, México, pp. 187-204.

Ramírez-Hernández, Fernando (2007), La politica de competencia y el proceso de regulación en México, Ed. Economía y Ciencias Sociales, Ciudad de México, México.

Rivera de la Rosa, Alba Rosa, Rafael Ortiz-Pech, Luis Alberto AraujoAndrade y Jesús Amílcar-Heredia (2014), "México y la autosuficiencia alimentaria (sexenio 2006-2012)", Revista Corpoica Ciencia y Tecnología Agropecuaria, Bogotá, Colombia, 15 (1), pp. 33-49.

Romero, Laura (2017), "EL TLCAN, desfavorable para el agro mexicano", Gaceta Digital UNAM, 6 de marzo, Universidad Nacional Autó- 
noma de México, Ciudad de México, México, <http://www. gaceta.unam.mx/20170306/el-tlcan-desfavorable-para-el-agromexicano/>, 24 de noviembre de 2017.

Roth-Deubel, André Noël (2014), Politicas públicas. Formulación, implementación y evaluación: Cómo elaborar las políticas públicas, Quien decide, Cómo realizarlas, Quien gana o pierde, Aurora Décima Edición, Bogotá, Colombia.

Roth Deubel, André-Noël (2007), "Análisis de las políticas públicas: de la pertinencia de una perspectiva basada en el anarquismo epistemológico", Ciencia Política, núm. 3, Universidad Nacional de Colombia, Bogotá, Colombia, pp. 44-68.

Rufin, Jean-Christophe (2004), "El nuevo rostro del hambre”, en Marc Ausias, (ed.), Geopolitica del hambre. Hambre: ¿Quién es el responsable? Informe 2003-2004, Edición Icaria, Barcelona, España, pp. $15-18$.

Rubio, Blanca (2013), La crisis alimentaria mundial: impacto sobre el campo mexicano, Miguel Ángel Porrúa, Ciudad de México, México.

Sagarpa (Secretaría de Agricultura, Ganadería, Desarrollo Rural, Pesca y Alimentación) (2010), Retos y oportunidades del sistema agroalimentario de México en los próximos 20 años, Secretaría de Agricultura, Ganadería, Desarrollo Rural, Pesca y Alimentación, Ciudad de México, México.

Sánchez-Juárez, Isaac Leobardo (2013), Politica industrial activa como estrategia para el crecimiento de la economía mexicana, Red Iberoamericana de Estudios del Desarrollo-Universidad Autónoma de Ciudad Juárez, Ciudad Juárez, México.

Sánchez-Toledano, Blanca, Jorge Zegbe-Domínguez, Agustín RumayorRodríguez, Georgel Moctezuma López (2013), "Estructura económica competitiva del sector agropecuario de Zacatecas: Un análisis por agrocadenas", Revista Mexicana de Agronegocios, XVII (33), SOMEXAA, Sonora, México, pp. 552-563.

Sánchez-Cano, Julieta Evangelina (2014), "La política agrícola en México, impactos y retos", Revista Mexicana de Agronegocios XVIII (35), 
Sociedad Mexicana de Administración Agropecuaria, Torreón, México, pp. 946- 956.

SELA (Sistema Económico Latinoamericano y del Caribe) (2007), Las asimetrías en los acuerdos de integración de América Latina y el Caribe, Sistema Económico Latinoamericano y del Caribe, Caracas, Venezuela.

TLCAN (Tratado de Libre Comercio de América del Norte) (2012), "El TLCAN hoy", Tlcanhoy.org, Ciudad de México, México, <http:// www.tlcanhoy.org/faq_es.asp\#faq-1>, 30 de agosto de 2016.

Tolón-Becerra Alfredo y Javier Lastra-Bravo (2008), "Desarrollo en espacios rurales Iberoamericanos. Sostenibilidad e indicadores", Observatorio Medioambiental, vol. 11, Universidad Complutense de Madrid, Madrid, Espańa, pp. 307-322.

Urquía-Fernández (2014), "La seguridad alimentaria en México", Revista Salud Pública México, 56 (1), Instituto Nacional de Salud Pública, Ciudad de México, México, pp. 92-98.

Vega, Mena Maricela de la, Vinicio Horacio Santoyo-Cortés, Manrrubio Muñoz-Rodríguez, Jesús Reyes Altamirano-Cárdenas (2013), "Cobertura financiera de la banca de desarrollo para el sector rural de México: FIRA y Financiera Rural”, Revista de Estudios Sociales, XXII (4), Universidad Autónoma Metropolitana unidad Iztapalapa, México, pp. 227-248.

Vela-Martínez Rafael y Petra Armenta-Ramírez (2015), La región sursureste de México: dependencia alimentaria y crisis agricola, Universidad Veracruzana/Instituto de Investigaciones jurídicas, Veracruz, México.

Viaquez, Luis (s/f), “Destinos y productos turísticos del México I”, Instituto Politécnico Nacional, Ciudad de México, México, <https://es.slideshare.net/hughorelax?utm_campaign=profiletracking\&utm medium=sssite\&utm_source=ssslideview $>, 10$ de enero de 2017 .

Villarespe-Reyes, Verónica y Ana Patricia Sosa-Ferreira (2008), "Políticas de combate a la pobreza en México: ¿solución, alivio o regulación del fenómeno?", Ponencia presentada en las XI Jornadas de Economía Crítica, 23 al 27 de marzo, Bilbao, España, <http://xxijhe. 
fahce.unlp.edu.ar/programa/descargables/villarespe_merino.pdfs, 10 de enero de 2017.

Vittrup-Christensen, Erik (2016), Índice de prosperidad urbana en la República Mexicana, ONU-Habitat, Ciudad de México, México.

Wooldridge, Jeffery (2010), Introducción a la Econometría, un enfoque moderno, Cengage Learning Editores, Ciudad de México, México.

Recibido: 29 de septiembre de 2017. Reenviado: 23 de noviembre de 2017. Aceptado: 15 de enero de 2018.

Louis Valentin-Mballa. Doctor en Ciencias Políticas por la Universidad Nacional Autónoma de México. Actualmente es profesor-investigador de la Universidad Autónoma de San Luis Potosí (UASLP) en la Facultad de Contaduría y Administración (FCA). Es líder del Cuerpo Académico Consolidado "Innovación y Gestión en las Organizaciones"; es coordinador de la maestría en Administración con énfasis en Gestión Pública del Programa de Estudios de Posgrado de la FCA-UASLP. Su línea de investigación actual es el análisis de las políticas públicas y sociales. Entre sus últimas publicaciones destacan: "Desarrollo local y microfinanzas como estrategias de atención a las necesidades sociales: un acercamiento teórico conceptual", Revista Mexicana de Ciencias Politicas y Sociales, XII (229), Universidad Nacional Autónoma de México-Nueva Época, Ciudad de México, México, pp. 101-128 (2017); "Public policies as a government challenge to fight against poverty in San Luis Potosî", GE-International Journal of Management, 3 (12), Research Associated Asia Research Foundation (AARF), Research Associated Asia Research Foundation, New Delly, Indian, pp. 99- 112 (2015) y Políticas públicas y complejidad: en búsqueda de solución a los problemas públicos, Miguel Ángel Porrúa, Ciudad de México, México (2017).

Arely Yesenia Sauceda-Quintero. Estudiante de licenciatura en la Facultad de Economía, Universidad de Zacatecas, México. 